\title{
RESENHA
}

Versão original| DOI: http://dx.doi.org/10.1590/S0034-759020210609

\section{MULTIDISCIPLINARIDADE NO (RE)PENSAR AS CIDADES NOS ESTUDOS ORGANIZACIONAIS}

\author{
HISTÓRIA, PRÁTICAS SOCIAIS E GESTÃO DAS/NAS CIDADES \\ Luiz Alex Silva Saraiva \& Ana Silvia Rocha Ipiranga (Eds.). Ituiutaba, MG: Barlavento, 2020. 379 p.
}

A cidade é um rico campo de pesquisa para os Estudos Organizacionais (EOS), que pode ser tratada tanto quanto um lócus como um objeto de pesquisa. De acordo com Knox (2010), as cidades vinham sendo pouco estudadas em termos organizacionais na Administração, sendo amplamente analisadas em termos geográficos, sociológicos e antropológicos, urbanísticos e econômicos. No entanto, esse cenário tem mudado no campo da Administração, em especial nos EOS brasileiros, visto que as cidades podem ser compreendidas a partir de uma vasta multidisciplinaridade desde uma organização complexa formada por diferentes teias que nos conectam de maneira pluralística e multidimensional (Fischer, 1997); de processos individuais, culturais e identitários inseridos num espaço-tempo (Mac-Allister, 2004); da territorialidade (Bretas \& Saraiva, 2013); da vida social organizada (Saraiva \& Carrieri, 2012); das práticas culturais estéticas do espaço urbano (Ipiranga, 2016); e até mesmo partir de um processo organizativo oriundo de diferentes práticas sociais e de organização (Franco \& Oliveira, 2017). A cidade deixou de ser apenas um lugar de moradia e (con)vivência, passando a ser entendida como uma organização contemporânea complexa constituída por diversos agentes e práticas produtores de signos, símbolos, significados e histórias, conforme apontado por Ipiranga (2010).

O livro organizado por Saraiva e Ipiranga amplia essa emergente gama de estudos, funcionando como um ótimo guia das possibilidades de realizar pesquisas científicas, em especial qualitativas, das/nas cidades, tanto de maneira metodológica quanto teórica. Assim como as cidades, este livro também é multidisciplinar, estando organizado em três partes, além do prefácio e introdução. A primeira foca na historicidade da cidade e das histórias que nelas são vividas, desde os conceitos de história de Walter Benjamin nos EOS (capítulo 1); a multidisciplinaridade entre a cidade e a literatura (capítulo 2); e como a urbanização modificou práticas de vivência e subsistência de uma comunidade quilombola (capítulo 3).

A segunda parte do livro chama atenção às práticas sociais que empregamos em nosso cotidiano, por exemplo, como o conceito de cidade global modifica as organizações, em específico, restaurantes requintados (capítulo 4); como a cidade de Belo Horizonte é representada por meio do Museu Brasileiro de Futebol (capítulo 5); como ocorrem as práticas de ciclismo utilitário em Fortaleza (capítulo 6); e a apropriação de um espaço público por uma empresa privada em Maringá (capítulo 7). Por fim, a terceira parte do livro destaca a gestão da cidade por meio da compreensão de que esta é organizada não apenas por seres humanos e artefatos, como também 
por animais não humanos (capítulo 8); e como os movimentos insurgentes podem ser dialogados em relação à gestão pública (capítulo 9).

Os artigos compilados neste livro evidenciam um ponto que já fora debatido por Figueiredo e Cavedon (2012): as cidades são sujeitas às apropriações físicas, materiais e simbólicas, criando-se, assim, seu espaço organizacional. Espaço esse, conforme nos relembram as autoras, que é resultado de diversas dinâmicas políticas, sociais e econômicas, como pode ser visto em Maricato (2017) em sua complexa análise do desenvolvimento das cidades e políticas urbanas no Brasil em anos recentes. Essas compreensões sobre a urbe permeiam o trabalho de Saraiva e Ipiranga, talvez não tão explicitamente, mas, assim como nas cidades, é necessário e recomendável que "andemos" pelos textos e criemos nossos próprios "caminhos".

Ademais, os artigos que fazem parte desta coletânea continuam a ampliar o olhar para os habitantes e praticantes das/nas cidades. Nesse sentido, podemos citar o avanço nos EOS brasileiros de temática urbana que englobam práticas e cidadãos poucos estudados na Administração, por exemplo, a população em situação de rua (Costa \& Oliveira, 2019; Honorato \& Saraiva, 2016); práticas espaciais de rupturas numa exibição de arte (Bezerra, Lopes, Silva, \& Ipiranga, 2019); práticas de pichação nas cidades (Viegas \& Saraiva, 2015); catador de materiais recicláveis (Rodrigues \& Ichikawa, 2015); entre outros. Nesse contexto, podemos enxergar a relevância de se realizar estudos nas cidades, estudar quem ali vive, como o cotidiano dessas pessoas se constitui nesse espaço, como a cidade constitui a vida desses sujeitos, entre tantas outras dinâmicas sociais.

As cidades, pois, não são um lugar apenas de moradia, são um espaço vivido e praticado por sujeitos humanos e não humanos em um fluxo de constante transformação (Certeau, 2008; Coimbra \& Saraiva, 2013). Ao decorrer da leitura, o leitor ou a leitora consegue perceber como as diferentes práticas sociais, organizativas e de gestão constituem a cidade, tanto de maneira histórica quanto cotidiana. A cidade é feita não só a partir de nossas vivências, mas também de nossas memórias e de nossos sentimentos. No entanto, é importante termos em mente, assim como o livro coloca em pauta, as forças políticas que estão presentes nesse espaço organizacional e que acabam constituindo, moldando, reforçando ou até mesmo impedindo nossas maneiras de praticar a cidade, assim como Certeau (2008) também nos alertou sobre a cidade-conceito e sua função arquitetônica e funcionalística.

Embora não seja o foco do livro em questão, futuras obras poderão trabalhar os aspectos da cidade-conceito voltados para a gestão da cidade, como o marketing urbano, que é uma ferramenta de gestão urbana que ajuda a reforçar a cidade-conceito, transformando as cidades em mercadorias (Duarte \& Czajkowski, 2007; Sánchez, 2001), abrindo espaço para o empresariamento urbano, conforme pontuado por Terci (2018). Por mais que as forças políticas permeiem os trabalhos apresentados no livro, elas não são necessariamente observadas de perto, sendo intrínsecas às práticas sociais que constituem as cidades. Dessa forma, seria interessante, também, trazer para a discussão dos EOS o outro lado da cidade, aquele que é gerenciado e controlado por poderes públicos e privados e como esses poderes lidam com as diferentes práticas históricas, culturais e sociais de seus habitantes.

Este livro, portanto, não esgota a temática e discussão sobre cidades dentro dos EOS, ele deve ser encarado como um compilado bem-articulado de textos de diferentes temáticas que nos relembram que a cidade é uma "mega-organização" (Fischer, 1996), ou seja, que dentro dela encontramos diversas formas, maneiras e processos organizativos que fazem outras organizações acontecerem. As cidades são um exemplo de coexistência organizacional cotidiana, que nos permite (re) pensar nosso olhar sobre elas, seus sujeitos, e as maneiras de fazer pesquisa nesse espaço organizacional.

Por fim, é importante ressaltar, como forma de disseminação do trabalho científico, que o livro encontra-se disponível gratuitamente para download no site: https://asebabaolorigbin.files.wordpress. com/2020/09/historias-praticas-sociais-e-gestao.pdf.

Boa leitura e boas reflexões!

\section{REFERÊNCIAS}

Bezerra, M. M., Lopes, L. L. S., Silva, J. S., \& Ipiranga, A. S. R. (2019). Spatial practices in the city: The kidnapping of an arts organization. Brazilian Administration Review, 16(4), 1-23. doi: 10.1590/1807-7692bar2019180163

Bretas, P. F. F., \& Saraiva, L. A. S. (2013). Práticas de controle e territorialidades na cidade: um estudo sobre lavadores e flanelinhas. GESTÃO.Org - Revista Eletrônica de Gestão Organizacional, 11(2), 247-270. Retrieved from https://periodicos. ufpe.br/revistas/gestaoorg/article/view/21921

Certeau, M. (2008). A invenção do cotidiano: 1. Artes de fazer (15 ed.). Petrópolis, RJ: Vozes.

Coimbra, K. E. R., \& Saraiva, L. A. S. (2013). Territorialidade em uma organização-cidade: O Movimento Quarteirão do Soul. Gestão \& Regionalidade, 29(86), 34-46. doi:10.13037/gr.vol29n86.2104

Costa, V. \& Oliveira, J. S. (2019). As emoções nas práticas de organização das cidades: Etnografia com a população em situação de rua na cidade de Maringá, Paraná. In XLIII Encontro da ANPAD - EnANPAD 2019, 1-16, São Paulo, SP. 
Duarte, F., \& Czajkowski Júnior, S. (2007). Cidade à venda: Reflexões éticas sobre o marketing urbano. Revista de Administração Pública, 41(2), 273-282. doi: 10.1590/So034-76122007000200006

Figueiredo, M. D., \& Cavedon, N. R. (2012). O espaço organizacional e o espaço da cidade: As diversas formas de apropriação física e simbólica de um centro comercial em Porto Alegre. Gestão e Sociedade, 6(15), 227-253. doi: 10.21171/ges.v6i15.1627

Fischer, T. (1996). Gestão contemporânea, cidades estratégicas: Aprendendo com fragmentos e reconfigurações do local. In T. Fischer (org.), Gestão contemporânea: Cidades estratégicas e organizações locais (pp. 13-23). Rio de Janeiro: FGV.

Fischer, T. (1997). A cidade como teia organizacional: Inovações, continuidades e ressonâncias culturais - Salvador, BA, cidade puzzle. Revista de Administração Pública, 31(3), 74-88. Recuperado de http:// bibliotecadigital.fgv.br/ojs/index.php/rap/article/view/7906v

Franco, B. L. \& Oliveira, J. S. (2017). Práticas organizativas e antropologia do direito no campo da cultura: Compreendendo a organização do forró pé de serra na luta pelos direitos à cidade em Brasília, Distrito Federal. In XLI Encontro da ANPAD - EnANPAD 2017, São Paulo, SP.

Honorato, B. E. F., \& Saraiva, L. A. S. (2016). Cidade, população em situação de rua e estudos organizacionais. Desenvolvimento em Questão, 14(36), 158-186. doi: 10.21527/2237-6453-2016-36.158-186

Ipiranga, A. S. R. (2010). A cultura da cidade e os seus espaços intermediários: Os bares e os restaurantes. Revista de Administração Mackenzie, 11(1), 65-91. doi: 10.1590/S1678-69712010000100004

Ipiranga, A. S. R. (2016). Práticas culturais de espaços urbanos e 0 organizar estético: Uma proposta de estudo. Revista Interdisciplinar de Gestão Social, 5(2), 105-123. Recuperado de https://rigs.ufba.br/ index.php/rigs/article/view/12527/11739
Knox, H. (2010). Cities and organisation: The information city and urban form. Culture and Organization, 16(3), 185-195. doi: 10.1080/14759551.2010.503496

Mac-Allister, M. (2004). A cidade no campo dos estudos organizacionais. Organizações \& Sociedade, 11(esp), 171-181. Recuperado de https://periodicos.ufba.br/index.php/revistaoes/ article/view/12642/8916

Maricato, E. (2017). The future of global peripheral cities. Latin American Perspectives, 44(2), 18-37. doi: 10.1177/0094582X16685174

Rodrigues, F. S., \& Ichikawa, E. Y. (2015). O cotidiano de um catador de material reciclável: A cidade sob o olhar do homem ordinário. Revista de Gestão Social e Ambiental, 9(1), 97-112. DOI: 10.24857/rgsa. vgi1.999

Sánchez, F. (2001). A reinvenção das cidades na virada de século: Agentes, estratégias e escalas de ação política. Revista de Sociologia e Política, 16, 31-49. Recuperado de https://revistas.ufpr.br/rsp/ article/view/3584

Saraiva, L. A. S., \& Carrieri, A. P. (2012). Organização-cidade: Proposta de avanço conceitual a partir da análise de um caso. Revista de Administração Pública, 46(2), 547-576. doi: 10.1590/So03476122012000200010

Terci, E. T. (2018). Processos urbanos e gestão local: Os casos de Ribeirão Preto e Piracicaba entre o empresariamento urbano e - Estatuto da Cidade. Cadernos EBAPE.BR, 16(3), 456-468. doi: $10.1590 / 1679-395166549$

Viegas, G. C. F. S., \& Saraiva, L. A. S. (2015). Discursos, práticas organizativas e pichação em Belo Horizonte. Revista de Administração Mackenzie, 16(5), 68-94. doi: 10.1590/1678. 69712015/administracao.v16n5p68-94

\section{CONTRIBUIÇÃO DO AUTOR}

Valdir Costa Junior trabalhou na conceitualização e abordagem teórica-metodológica, na revisão teórica, da redação e revisão final do manuscrito. 